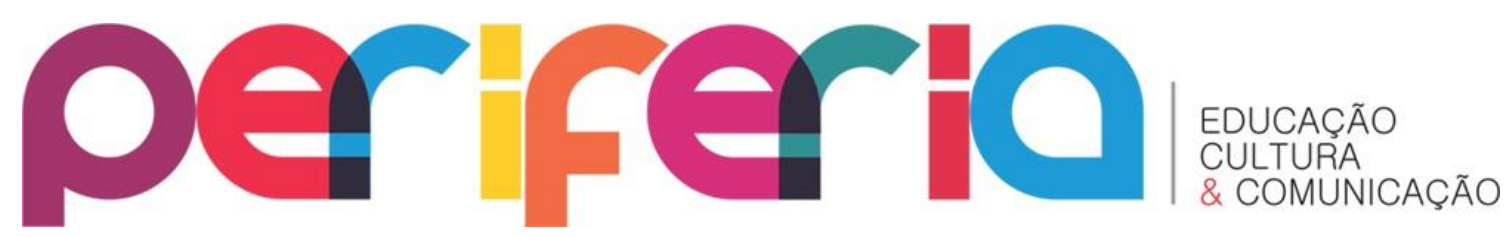

\title{
ACCOUNTABILITY E EDUCAÇÃO BÁSICA NA REDE MUNICIPAL CARIOCA: CONTRIBUIÇÕES PARA O DEBATE SOBRE QUALIDADE NA EDUCAÇÃO.
}

\author{
Virgínia Louzada ${ }^{1}$ \\ Instituto Benjamin Constant
}

\section{RESUMO}

Busco, neste artigo, discutir o processo de avaliação instituído na educação básica da rede pública municipal do Rio de Janeiro. Tendo como referência os estudos sobre a avaliação, utilizo o conceito de accountability para problematizar as concepções de eficiência e qualidade que orientam as políticas e as práticas pedagógicas. Entendo que o pano de fundo de tais políticas objetiva melhorar os indicadores nas avaliações externas e em larga escala a que os/as alunos/as serão submetidos em toda a escola básica e nos anos posteriores, avaliações estas realizadas pela Secretaria Municipal de Educação (SME/Rio) e pelo governo federal. Tal contexto visa a melhoria de indicadores em avaliações nacionais e internacionais, como o PISA.

Palavras-chave: accountability; avaliação externa; qualidade.

\section{ACCOUNTABILITY AND BASIC EDUCATION OF CARIOCA PUBLIC EDUCATIONAL SYSTEM: CONTRIBUTING TO THE QUALITY EDUCATION DEBATE. ABSTRACT}

In this article, I intend to discuss the evaluation process established in the basic education of the public schools of Rio de Janeiro. With reference to the evaluation studies, I use the concept of accountability to question the concept of efficiency and quality that guides the policies and pedagogical practices. I understand the background of such policies aimed at improving the indicators and external evaluations on a large scale that all students will be submitted throughout the elementary school and in later years - these tests conducted by the Municipal Education (SME/Rio) and the federal government. This scenario aims at improving indicators in national and international assessments like PISA

Keywords: accountability; external evaluation; quality.

\section{PARA INÍCIO DE CONVERSA...}

Interessada em atingir as metas estabelecidas pelo governo federal em relação ao IDEB (Índice de Desenvolvimento da Educação Básica) no ensino fundamental, a gestão Eduardo Paes/Claudia Costin instituiu, na rede, a partir de 2009, duas novas

\footnotetext{
${ }^{1}$ Doutoranda em Educação do Programa de Pós-Graduação em Educação da Universidade Federal Fluminense, dos Estudos do Cotidiano e da Educação Popular. Professora do Instituto Benjamin Constant. E-mail: virginialouzadari@gmail.com
} 


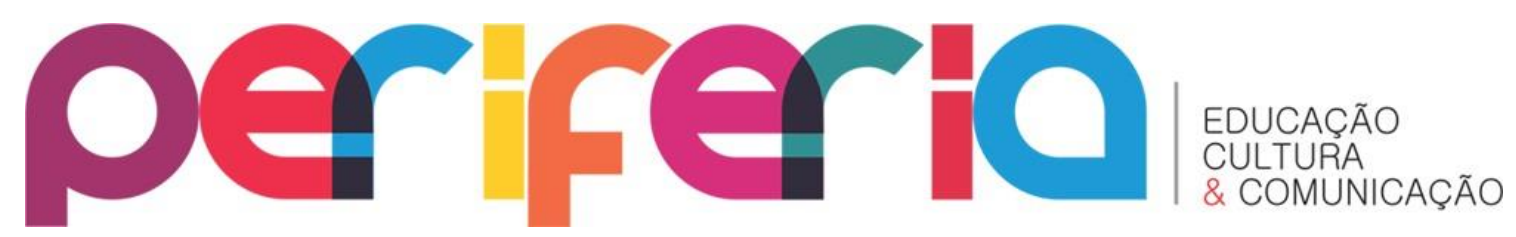

modalidades avaliativas: a Prova Rio e as Avaliações Bimestrais da Rede. A Prova Rio é uma avaliação anual realizada através de testes de múltipla escolha de Língua Portuguesa e Matemática que seguem os moldes da Prova Brasil. O processo de preparação para esta prova é feito através de exercícios e correções dos conteúdos que serão avaliados e a realização de simulados nos diversos anos de escolaridade nesta etapa da educação básica.

A Prova Rio é uma avaliação externa de Português e Matemática aplicada em alunos do 3으, 4으, 7으 e 8o anos matriculados na rede. Ela gera o IDERIO (Índice de Desenvolvimento da Educação do Rio) e também foi aplicada pela primeira vez em 2009, fato que não pode ser considerado uma mera coincidência. Neste ano, Eduardo Paes assumiu seu primeiro mandado como prefeito da cidade e nomeou Claudia Costin como secretária municipal de educação. O início desta gestão foi marcado por declarações de que a educação municipal carioca não ia bem e que precisava de atitudes contundentes para alcançar uma "qualidade" maior do a da gestão anterior.

As Avaliações Bimestrais da Rede são testes de múltipla escolha de Língua Portuguesa, Matemática e Ciências, aplicados a todos os anos de escolaridade do ensino fundamental. Seus resultados compõem a nota média do aluno. Estas avaliações estão articuladas a dois outros instrumentos didáticos introduzidos pela mesma política: os Descritores de Ensino (listas bimestrais de habilidades e conteúdos para as Avaliações Bimestrais da Rede) e os Cadernos de Apoio Pedagógico (apostilas bimestrais de exercícios para preparar os/as alunos/as para a Avaliação Bimestral da Rede); material este produzido por professores/as da SME/Rio para todos os anos do ensino fundamental (inclusive para a pré-escola, uma das modalidades da educação infantil). Além destas avaliações, a SME/Rio ainda instituiu a prova Alfabetiza Rio, para verificar o desempenho dos alunos e alunas em Língua Portuguesa e Matemática ao final do 10 ano do ensino fundamental, ou seja, para os/as alunos/as recém egressos da educação infantil.

Em âmbito federal, ainda nesta etapa da educação básica, as escolas da rede pública carioca são submetidas às avaliações externas promovidas pelo INEP (Instituto 


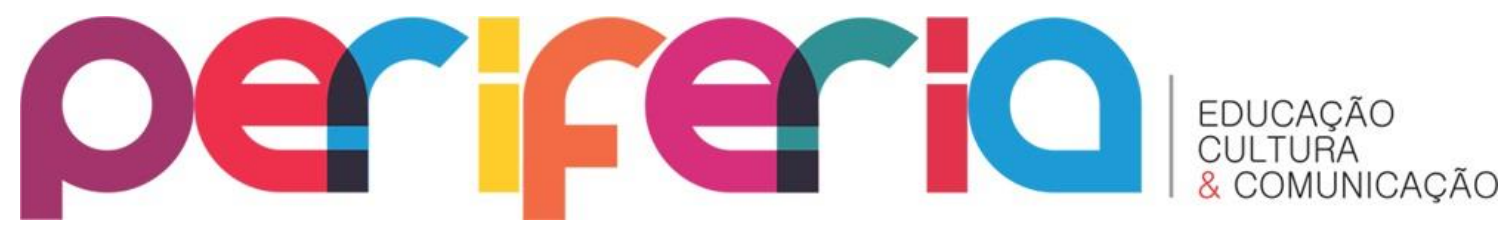

Nacional de Estudos e Pesquisas Educacionais Anísio Teixeira), órgão do MEC (Ministério da Educação). O SAEB (Sistema de Avaliação da Educação Básica) tem como objetivo avaliar a educação básica brasileira e (re)formular/monitorar as políticas públicas voltadas para esta faixa etária. O SAEB é composto por três avaliações externas e em larga escala, a saber: ANEB (Avaliação Nacional da Educação Básica), ANRESC (Avaliação Nacional do Rendimento Escolar) e ANA (Avaliação Nacional da Alfabetização).

A ANEB é realizada por amostragem nas redes públicas e privadas de ensino, em cada unidade da federação, em alunos/as matriculados/as no 5o e no 9o ano do ensino fundamental e no 3ำ ano do ensino médio. A ANRESC, também denominada Prova Brasil, é uma avaliação censitária envolvendo alunos/as do 5으 ano e 9o ano do ensino fundamental das escolas públicas das redes municipais, estaduais e federal do país. A ANA é uma avaliação censitária dos/as alunos/as do 3o ano do ensino fundamental das escolas públicas, para avaliar-Ihes os níveis de alfabetização em Língua Portuguesa e em Matemática. Foi incorporada ao SAEB em 2012. As duas primeiras avaliações são realizadas a cada dois anos; a ANA, anualmente.

Esta política de avaliação, pautada em avaliações externas e em larga escala, é compreendida como sinônimo de "qualidade" para a educação pública. Neste sentido, o Estado brasileiro possui outros programas de avaliação, em diferentes anos de escolaridade e modalidades de ensino:

$\checkmark$ Provinha Brasil - avaliação aplicada no início e no final do 2o ano do ensino fundamental;

$\checkmark$ Exame Nacional para Certificação de Competências de Jovens e Adultos (ENCCEJA).

$\checkmark$ Exame Nacional do Ensino Médio (ENEM) - avaliação do ensino médio, também utilizada para ingresso nas universidades;

$\checkmark$ Sistema Nacional de Avaliação da Educação Superior (SINAES)

$\checkmark$ Exame Nacional de Desempenho dos Estudantes (ENADE).

Em âmbito internacional, nosso país participa do PISA (Programa Internacional de Avaliação de Estudantes), que é uma iniciativa internacional/supranacional de avaliação comparada, aplicada a estudantes na faixa etária dos 15 anos, idade em que 


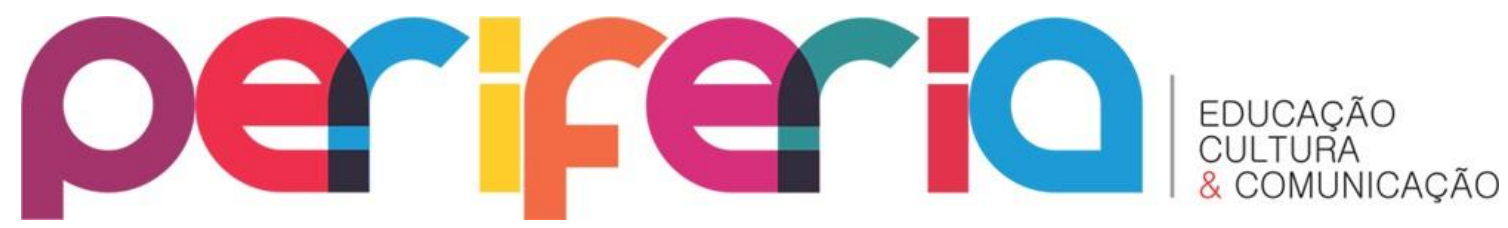

se pressupõe o término de escolaridade básica obrigatória na maioria dos países membros da OCDE (Organização para Cooperação e Desenvolvimento Econômico). O programa é desenvolvido e coordenado por esta organização. Em cada país participante há uma coordenação nacional. No Brasil, o PISA é coordenado pelo INEP. As avaliações do PISA acontecem a cada três anos e abrangem três áreas de conhecimento - Leitura, Matemática e Ciências - havendo, a cada edição do programa, maior ênfase em uma área. Em 2000, o foco foi em Leitura; em 2003, Matemática; e em 2006, Ciências. Em 2009 o PISA iniciou um novo ciclo do programa, com o foco novamente recaindo sobre o domínio de Leitura; em 2012, em Matemática; e em 2015, Ciências.

Pensando nas avaliações externas e em larga escala produzidas pelo INEP para os anos iniciais do ensino fundamental, a Avaliação da Alfabetização Infantil, conhecida como Provinha Brasil, foi instituída em 2007 e foi implementada no ano seguinte. Trata-se de um instrumento de avaliação, aplicado no início e no término do $2 \stackrel{9}{\text { ano do }}$ ensino fundamental, utilizado para monitorar os processos de desenvolvimento da alfabetização oferecida nas escolas públicas brasileiras, após um ano de estudos.

Além destas avaliações, há os programas de estatísticas educacionais, como o IDEB, citado anteriormente neste texto, que mede cada escola e sistema de ensino, servindo-se de base para metas educativas; os Censos Educacionais (Educação básica e Ensino Superior) e Cadastros (Docentes e Instituições de Educação Superior). O IDEB é considerado como o principal indicador para o desenvolvimento da avaliação municipal, a partir do monitoramento do sistema de ensino. Foi criado pelo INEP em 2007 e surgiu da combinação de dois elementos: os indicadores de fluxo (referentes à promoção, repetência e evasão) e as pontuações em exames padronizados obtidas por estudantes ao final de determinada etapa. $\mathrm{O}$ indicador é calculado a partir dos dados sobre aprovação escolar (obtidos no Censo Escolar) e médias de desempenho nas avaliações do INEP - o SAEB (para as unidades da federação e para o país) e a Prova Brasil (para os municípios). A partir dos resultados, é feito um ranking entre as escolas. 


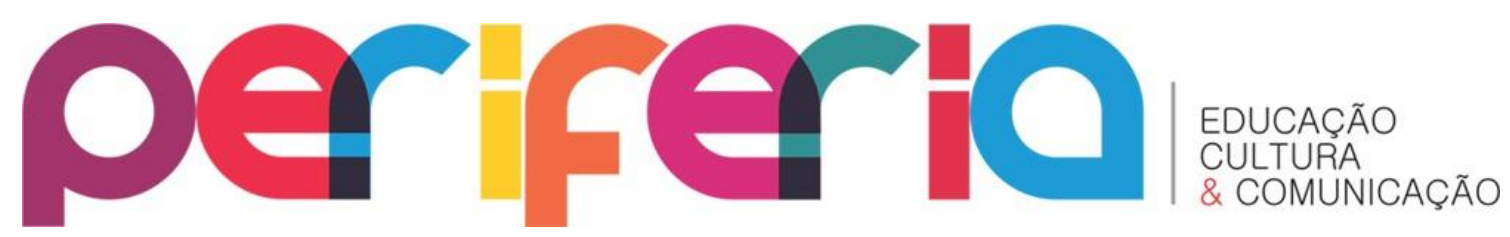

No período compreendido entre 1990 e 1993, o MEC delegou ao INEP as ações de coordenação e administração do sistema de avaliação da educação básica. Para Freitas (2007), em 1997 este órgão passou a concentrar ações de levantamento e análise da educação brasileira, estabelecendo articulação com o IBGE e com o IPEA, em associação a organismos internacionais como Unesco e OCDE.

No entendimento de Hypolito (2010), políticas curriculares desenvolvidas no contexto de uma globalização em moldes neoliberais têm orientado as ações do Estado no campo educacional como forma de regulação social. Freitas e outros (2012) ressaltam que regulação foi um termo construído no interior das políticas públicas neoliberais, a fim de transferir o poder de regulação do Estado para o mercado, para conseguir a privatização do público. Hypolito argumenta que estas políticas produzem efeitos importantes no currículo, na gestão e no trabalho docente. Por meio de estratégias de avaliação consideradas gerencialistas, "[...] o Estado tem obtido êxito na padronização curricular, na implantação de políticas de formação docente e na submissão da escola e da educação aos interesses do mercado" (2010, p. 1337). A introdução de sistemas da avaliação da educação e do desempenho docente para a regulação por parte do Estado se apresentam como a solução para os problemas da educação, mas acabam sendo insuficientes para enfrentá-los.

Ainda para o autor, esta realidade não é exclusiva da rede pública municipal do Rio de Janeiro. Inúmeros municípios brasileiros, com o objetivo de alcançar as metas estabelecidas pelo Estado regulador e por seus estudos de avaliação, elaborados por órgãos como o INEP, utilizam os resultados obtidos na avaliação externa como parâmetro de qualidade para a educação e organizam os processos de regulação do trabalho docente através da implementação de exames, de certificação do currículo e da gestão escolar. A introdução destes sistemas de avaliação - da educação e do desempenho docente - é essencial para efetivar a regulação, uma vez que, com isso, o Estado entende que passa a controlar as práticas educativas, preferencialmente através de terceiros (no caso dos municípios), contratados para realizar a avaliação, principalmente externa e em larga escala, baseada em princípios de qualidade e 


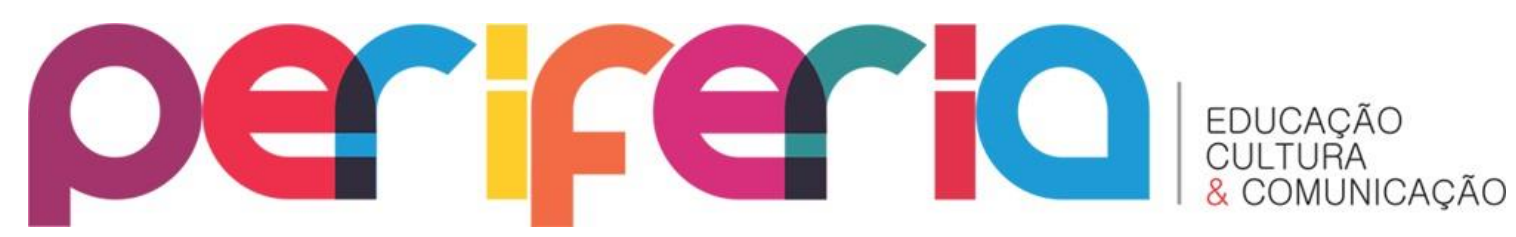

mérito, na tentativa de reduzir os problemas da educação a problemas técnicosgerenciais.

O autor pondera que o neoliberalismo em educação precisa ser entendido como uma política de regulação do Estado e não como uma política educacional de governo. Através do discurso de que as reformas são uma necessidade natural e parte inevitável da globalização e do mercado internacional, desloca-se a esfera do político para a esfera do econômico (pretensamente desprovido de política), fato este que passa a ser determinante para as definições educativas. Neste contexto, a avaliação de produtos e de desempenho é considerada imprescindível para se alcançar a eficiência, a qualidade e a solução de problemas educacionais.

Sousa (2001) ressalta que, a partir da década de 90, a avaliação vem se constituindo em um dos elementos estruturantes das políticas educacionais em curso no Brasil, apesar dos diferentes focos que pode ter em todos os níveis do sistema de ensino. Tradicionalmente, o foco privilegiado era a avaliação da aprendizagem, porém, atualmente, também é possível observar propostas e práticas que se voltam para avaliação do desempenho docente, avaliação de curso, avaliação institucional e avaliação do sistema educacional. Tais propostas e práticas abrangem os diversos níveis de ensino: a educação básica, o ensino de graduação e a pós-graduação.

Hypólito (2010) argumenta que, entre outras funções, a avaliação também pode ser considerada um processo de prestação de contas à sociedade civil nomeado accountability (este termo, de origem inglesa, ainda não possui tradução para a língua portuguesa). Neste contexto, pondera que as ações do Estado gerencial e as políticas educativas têm um caráter regulador que determina, em boa medida, as identidades docentes, objetivando torná-las adequadas a tais empreendimentos educativos, a partir da introdução cada vez mais abrangente da lógica do mercado no interior das escolas e através de intervenções pedagógicas providenciadas pela parceria públicoprivado, terceirização de serviços e outras formas.

Afonso (2010) amplia a discussão sobre o conceito de accountability, pois considera que, embora o vocábulo seja frequentemente utilizado como prestação de 


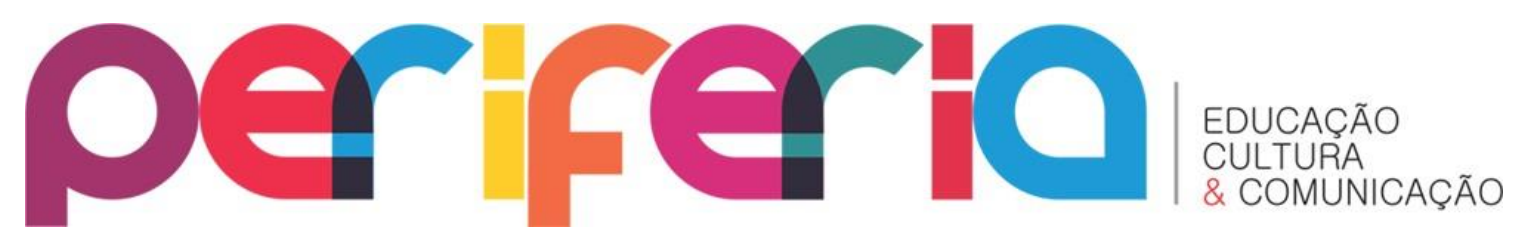

contas, apresenta certa instabilidade semântica. Para este autor, é um conceito que corresponde a significados e amplitude plurais, uma vez que "[...] remete para políticas, sistemas, modelos, dimensões, agências, práticas e atores também diversificados" (p. 149), parecendo ser um conceito em expansão cujas interpretações nem sempre convergem. Carvalho e Macedo (2010) afirmam que este conceito se refere às avaliações em larga escala, instituídas legalmente pelo poder público, com datas previamente determinadas, em âmbito nacional e estadual, elaboradas externamente às unidades escolares, para os sistemas de ensino. Os resultados são sistematizados e publicados. Geralmente subsidiam políticas públicas e intervenções pedagógicas.

Em outro texto de Afonso (2012), o autor pondera que a necessidade de implementar certas formas de accountability transformou-se em um fetiche, pelo fato de se supor que a avaliação, a prestação de contas e a responsabilização são capazes de satisfazer as expectativas de grupos e setores sociais aparentemente interessados em resolver os problemas de qualidade da educação pública. Grande parte dos discursos marcados por este viés político-ideológico reduzem o significado do vocábulo accountability a uma forma tecnocrata e gerencialista de prestação de contas que dá ênfase a imputações negativas e estigmatizantes, que muitas vezes carregam formas autoritárias de responsabilização das instituições, organizações e indivíduos. Neste contexto, os processos de responsabilização ou de prestações de contas passam a ser mais importantes do que os processos pedagógicos.

Ao longo das últimas décadas, o governo federal, alguns governos estaduais e municipais implementaram em suas redes de ensino, gradativamente, avaliações em larga escala padronizadas que se propõem a melhorar a qualidade da educação oferecida, por meio de monitoramento das escolas e de reorientação das políticas públicas, a partir de mecanismos de medida do índice de desempenho dos alunos e alunas. Afonso pondera que "[...] a partir da década de oitenta, o interesse demonstrado pela avaliação, sobretudo por parte de governos neoconservadores e neoliberais, começou a ser traduzido pela expressão Estado-avaliador" (2000, p. 49). 0 


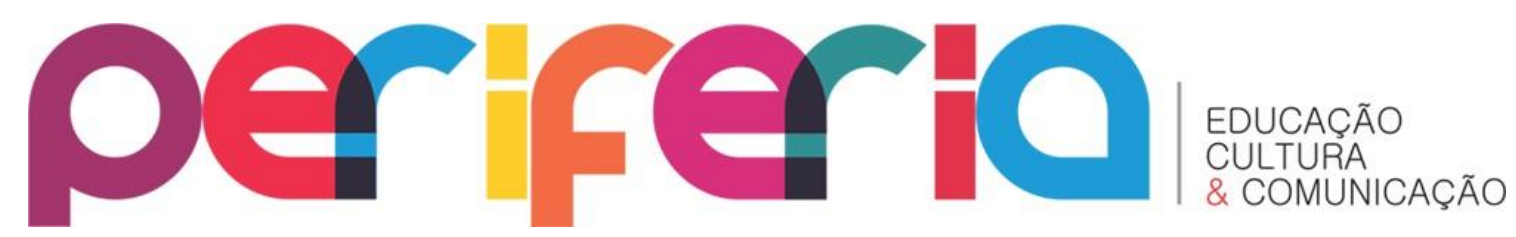

autor explica que esta expressão significa que o Estado vem adotando um ethos competitivo, neodarwinista e, através da importação para o domínio público de modelos de gestão privada, com ênfase nos resultados dos sistemas educativos, passa a admitir a lógica do mercado e a criação de mecanismos de controle e responsabilização cada vez mais sofisticados.

Uma das mudanças importantes - no contexto educacional e fora dele - é a ênfase genérica nos resultados (e produtos), em detrimento da avaliação dos processos. Ainda para este autor, as propostas deste Estado favorecem a "desvalorização da multirreferencialidade dos processos avaliativos" (AFONSO, 2000, p. 49) e representam um retrocesso considerável aos pressupostos positivistas e quantitativistas. O Estado Avaliador é o responsável pela imposição de um currículo nacional comum e pelo controle dos resultados, sendo a avaliação a principal ferramenta para se alcançarem os objetivos do Estado neoliberal, tornando-se uma importante estratégia para o gerenciamento da educação.

O contexto social em que tais resultados são produzidos é desconsiderado, a partir de uma pressuposta "qualidade" de ensino, tendo como princípio conceitos como eficiência e seletividade do sistema educacional. Ganham força as políticas centradas em ações que incentivam a terceirização da administração do sistema público e as parcerias público-privado que, no caso do Rio de Janeiro, podem ser traduzidas nas parcerias com o Instituto Alfa e Beto, Instituto Sangari, Instituto Ayrton Senna e Fundação Roberto Marinho, entre outras.

Hypolito (2010) ressalta que inúmeros municípios brasileiros, assim como o Rio de Janeiro, têm buscado apoio nestas empresas (e outras) para garantir o "sucesso" da educação e alcançar a tão desejada "qualidade", através dos programas de intervenção pedagógica. Inserido nas reformas neoliberais, o conceito de qualidade se vincula aos métodos quantitativos de avaliação, justificados a partir da meritocracia, ou seja, da individualização dos resultados. A responsabilização pelo fracasso da educação pública passa a sofrer uma "descentralização da culpa" (HYPOLITO, 2010, p. 


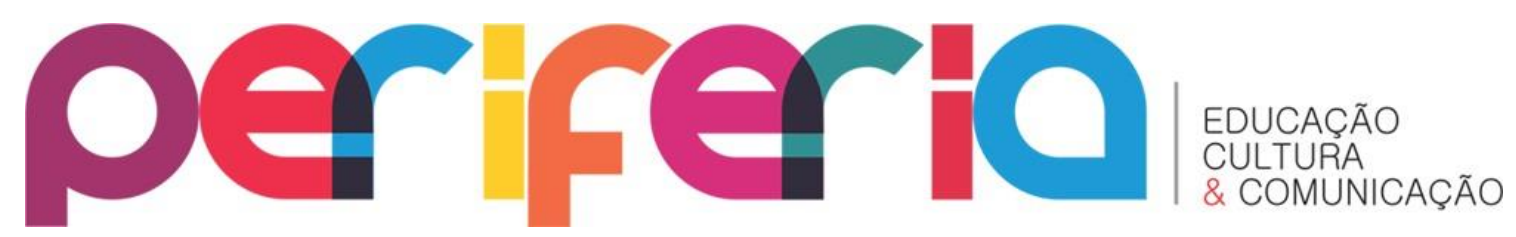

1343), uma vez que a "falta" desta qualidade recai, em última instância, sobre as escolas, o corpo docente, os estudantes e os pais.

Inserido neste contexto, no município do Rio de Janeiro há uma maior intervenção de instituições externas, como foi dito anteriormente: falando especificamente das avaliações, temos as provas anuais de rede (Prova Rio), a publicação de rankings de desempenho, as avaliações bimestrais enviadas pela SME/Rio e as avaliações nacionais.

A intenção de premiação a partir do desempenho dos/as alunos/as nas avaliações externas se materializa com o Prêmio Anual de Desempenho, a partir da lógica da produtividade, através de um salário adicional para professores/as e funcionários/as das escolas regulares e um salário e meio para os/as professores/as e funcionários/as do Projeto Escolas do Amanhã. Para Sousa (2001, p. 88), “[...] a questão central nesta proposta não é buscar subsídios [...], mas sim instalar mecanismos que estimulem a competição entre as escolas, responsabilizando-as, em última instância, pelo sucesso ou fracasso escolar".

Infelizmente nem a primeira infância está isenta desta lógica, uma vez que, para a sua eficácia, necessita estar presente em todo o sistema e não em frações dele. Apesar da ausência de resultados quantificáveis ou de índices como IDEB na educação infantil, na rede municipal carioca tivemos a aplicação de questionários denominados ASQ-3 (Ages and Stages Questionnaries) e ASQ-SE, que foram preenchidos pela equipe pedagógica. O ASQ-3 trata-se de um modelo de avaliação desenvolvido nos Estados Unidos por uma equipe multidisciplinar. A primeira versão dele foi feita em 1997 e a terceira versão, em 1999 (que foi a versão utilizada na rede municipal carioca). O objetivo principal da aplicação do teste foi detectar atrasos no desenvolvimento infantil (NEVES, 2012).

O ASQ-3 foi utilizado de maneira experimental no município do Rio de Janeiro, em parceria com a Secretaria de Assuntos Estratégicos (SAE) da Presidência da República, em 2010. Inicialmente, foi aplicado nas creches por amostragem. Nos anos seguintes (2011 e 2012), foi aplicado em toda a educação infantil da rede. A intenção 


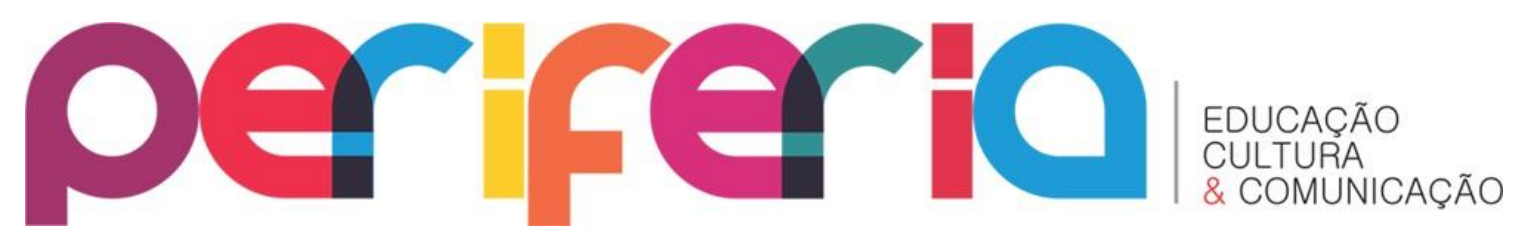

era estender a aplicação dos questionários para outras redes públicas do país, fato este que não se concretizou. A partir da tabulação dos resultados, foram estabelecidos dois ranqueamentos: um interno (entre as creches e escolas de uma mesma Coordenadoria Regional de Educação) e um geral, para toda a rede.

Gostaria de ressaltar que a adoção indiscriminada de instrumentos de avaliação como o ASQ-3, pautados em padrões universais de criança e desenvolvimento infantil é algo muito perigoso, principalmente por que o mesmo toma como padrão de excelência a classe média branca estadunidense (NEVES, 2012), desconsiderando os contextos culturais em que estas crianças cariocas estão inseridas e desfavorecendo uma reflexão da criança como sujeito social. Além disto, o instrumento desconsidera os próprios documentos oficiais sobre a primeira infância que preconizam avaliar a infraestrutura física, o quadro de pessoal e os recursos pedagógicos, não a criança individualmente. O Referencial Curricular Nacional para a Educação Infantil (BRASIL, 1998) propõe, em seus três volumes, que a avaliação seja formativa, diagnóstica e que oriente a prática educativa do/a professor/a. "[...] não se trata de avaliar a criança, mas sim as situações de aprendizagem que foram oferecidas." (BRASIL, 1998, p. 65). As Diretrizes Curriculares Nacionais para a Educação Infantil (BRASIL, 2009) também preconizam uma avaliação processual, diagnóstica e formativa, que possa oferecer subsídios para o planejamento das práticas educativas.

Além da aplicação dos questionários do ASQ-3, em agosto de 2010 foi instituído, pela SME/Rio, o Prêmio Anual de Qualidade para a educação infantil e para a educação especial. A premiação tem por objetivo recompensar os professores/as que prestam atendimento exclusivo à educação infantil e à educação especial a partir de projetos pedagógicos anuais avaliados por uma Comissão Especial constituída para este fim. O prêmio corresponde ao valor de uma remuneração mensal individual do servidor, desde que esteja em exercício efetivo na unidade educacional durante todo o período letivo e não ultrapasse o período máximo de cinco dias de ausência ao trabalho. 


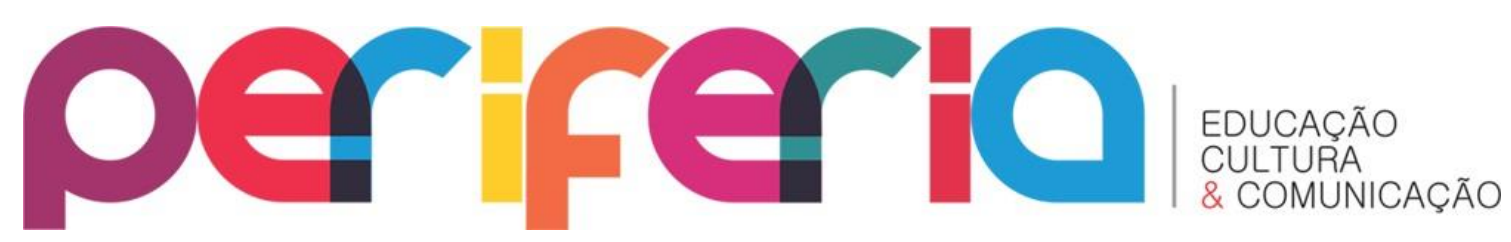

Em 2012, o governo federal, através do MEC, lançou o PNAIC (Pacto Nacional pela Alfabetização na Idade Certa). O Pacto é um compromisso formal assumido pelo Governo Federal, Distrito Federal, estados e municípios brasileiros para assegurar que todas as crianças estejam alfabetizadas até os oito anos de idade, ao final do 30 ano do ensino fundamental. Ao aderir ao Pacto, os entes governamentais se comprometem a: alfabetizar todas as crianças em língua portuguesa e matemática; realizar avaliações anuais universais (grifo meu), aplicadas pelo INEP, junto aos concluintes do 30 ano do ensino fundamental; no caso dos estados, apoiar os municípios que tenham aderido às Ações do Pacto, para sua efetiva implementação. Ainda de acordo com esta portaria, a Provinha Brasil passou a assumir uma nova dinâmica de funcionamento, oferecendo dados ao Governo Federal sobre a realidade dos Estados, do Distrito Federal e dos Municípios².

Inseridos/as neste contexto de valorização da alfabetização e do PNAIC, ainda no ano de 2012, os/as professores/as alfabetizadores da rede e os/as diretores/as das escolas da rede municipal carioca assinaram o Pacto Carioca pela Alfabetização, seguindo os mesmos moldes do PNAIC. No mesmo contexto dos pactos podemos encontrar a divulgação do ranking dos melhores resultados na Prova Alfabetiza Rio, prova aplicada no 1 - ano do ensino fundamental da rede municipal carioca, a partir da pontuação obtida pelos professores/escolas responsáveis pelas turmas de 10 ano do ensino fundamental ${ }^{3}$ :

\footnotetext{
${ }^{2}$ Disponível em: <http://pacto.mec.gov.br/o-pacto〉. Acesso em: 05 ago. 2014.

${ }^{3}$ Disponível em: <http://www.rioeduca.net/blogViews.php?bid=20\&id=3409>. Acesso em: 08 maio 2014.
} 


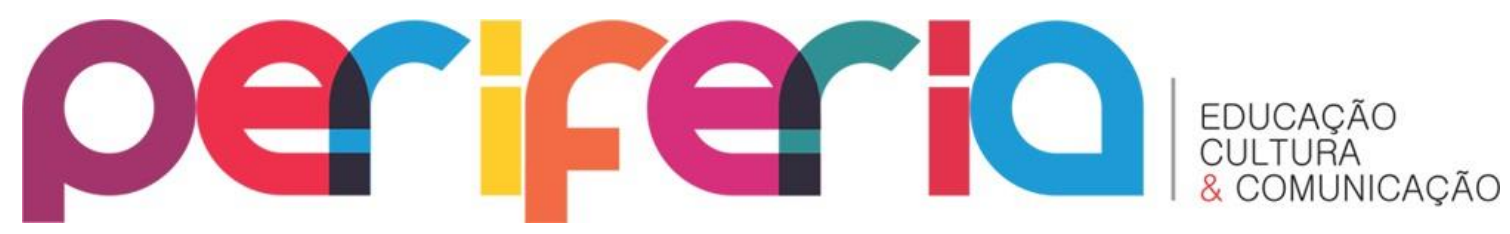

\begin{tabular}{|c|c|c|c|c|c|}
\hline \multicolumn{6}{|c|}{ Responsáveis pelas turmas com melhores desempenhos - Fonte: Prefeitura do Rio de Janeiro } \\
\hline ORDEM & Protessota & CRE & Escola muricipal & Bairto & Méda \\
\hline 1 , & CASSILDA ALVEIDA DOS SANTOS & $10^{*}$ & CIEP 1' DE NAIO & SANTA CRUZ & 233.8 \\
\hline $2^{*}$ & URANIA SOUZA DOS SANTOS & $6^{*}$ & OCTAVIO TARQUINIO DE SOUZA & PAVUNA & 233.7 \\
\hline $3^{*}$ & CARLA PANA DE MESQUTTA & $10^{*}$ & JOKO GUALBERTO JORGE DO A MARAL & PACIENCLA & 233,1 \\
\hline $4^{*}$ & NARIA APARECIDA BRAGA DE OLIVEIRA & 6" & PROFESSOR ESCRA GNOLLE DORIA & COSTA BARROS & 221.4 \\
\hline $5^{*}$ & RENATA APARECIDA YARUANO DANASCENA HENRIQUES & 7 & PROFESSOR JURANOIR PAES LEME & RECREIO & 2313 \\
\hline $6^{\circ}$ & ADRIA NA RODRIGUES KREUPSER & 5. & GASPAR VIANNA & IRAJA & 230,7 \\
\hline $7^{*}$ & CATIA LORETTI GONSSALVES DA SLVA & 5* & CERVANTES & BENTO RIBEIRO & 230.5 \\
\hline $8^{*}$ & LUCIA REJANE DA SILVA & $10^{*}$ & DOUTOR NELSON HUNGRIA & PACIENCIA & 2305 \\
\hline$g$ & NARISTELA NARTINS & $4^{\prime}$ & NOVA HOLANDA & COYPLEXO DA MARE & 230,1 \\
\hline $10^{\circ}$ & MONICA VARIA WEINSTEIN IOZZI DIAS & $2^{\prime}$ & ESTÁCIO DE SA & URCA & 230,1 \\
\hline $11^{*}$ & ALZENATE ANCELNE DIAS & $4^{*}$ & LUIZ CESAR SAYÃO GARCEZ & OLARIA & 2297 \\
\hline $12^{\circ}$ & CLAUDU MARIA DE SOUZA CRUZ & $6^{*}$ & ARTUR A ZEVEDO & PAVUNA & 229.6 \\
\hline
\end{tabular}

A meu ver, a divulgação do ranqueamento dos resultados na prova Alfabetiza Rio e a utilização de material pedagógico na pré-escola se justificam a partir da lógica de preparar as crianças para as avaliações externas e em larga escala a que serão submetidas durante os três primeiros anos do ensino fundamental, antecipando-lhes a alfabetização para a pré-escola; também iniciam-lhes a preparação para as avaliações externas e em larga escala a que serão submetidas nos demais anos de escolaridade, corroborando a premissa de que cada vez mais cedo estão sendo submetidas à lógica da avaliação classificatória, que tem como função diferenciar, comparar, discriminar, padronizar e hierarquizar os sujeitos e seus processos de aprendizagem.

\section{E POR FALAR EM QUALIDADE...}

De acordo com as notas técnicas do Ministério da Educação (CONSELHO NACIONAL DE EDUCAÇÃO, 2010), que avaliam as metas 1, 2 e 3 do Plano Nacional de Educação para o decênio 2010-2020 (BRASIL, 2010), o fluxo escolar brasileiro está muito longe do desejável. Tendo como parâmetro de qualidade o cenário internacional, argumenta que, no ano de 2009, no nosso país, a aprovação média por 


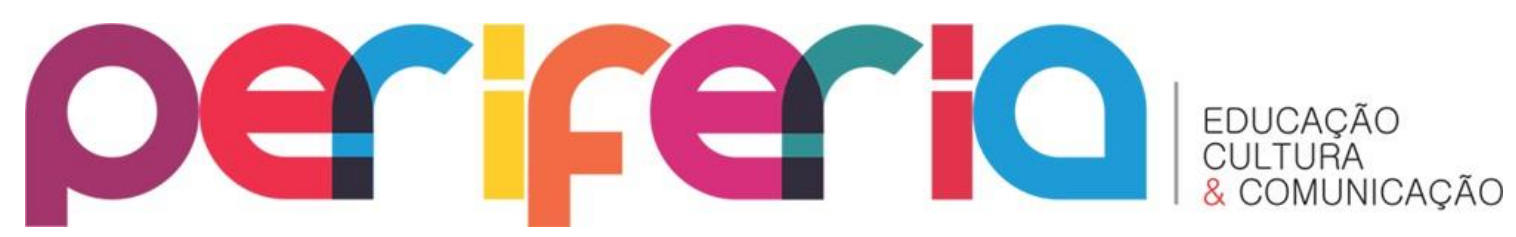

nível de ensino foi de $88,5 \%$, para os anos iniciais do ensino fundamental, de $81,3 \%$ para os anos finais e de 75,9\% no ensino médio, enquanto a taxa média de aprovação no grupo de países membros da OCDE era de 96\% em 2005 (ano base para o IDEB). O mesmo documento afirma que o investimento na primeira infância torna possível elevar o desempenho das crianças e jovens na educação básica e que um ambiente familiar adverso ao desenvolvimento de habilidades infantis pode ser compensado por intervenções no início do desenvolvimento infantil, aumentando o retorno do investimento no período seguinte.

Ainda para o documento (CONSELHO NACIONAL DE EDUCAÇÃO, 2010), vários estudos internacionais evidenciam que os cuidados na primeira infância determinam, entre outras coisas, melhor desempenho nos testes de inteligência e menores taxas de repetência e evasão escolares. Felicio e Vasconcellos (2007), por exemplo, afirmam que frequentar a pré-escola pode elevar o resultado do SAEB, em média, entre $9 \%$ e 19\%, dependendo da região do país.

Pensando neste contexto das avaliações externas, Sousa (2001) nos alerta que os diversos níveis de ensino têm sido avaliados pelo poder público a partir da justificativa de que esta avaliação pode "produzir" um ensino de melhor qualidade. Apesar das especificidades de cada um destes níveis de ensino, algumas características se fazem comuns nos procedimentos adotados, tais como: ênfase nos produtos (ou resultados); valorização de princípios meritocráticos, a partir da individualização das instituições e/ou alunos; dados escalonados de desempenho, transformados em classificação; dados predominantemente quantitativos e destaque para as avaliações externas desvinculadas da autoavaliação, em um processo em que cada vez mais se diluem as fronteiras entre educação e mercado.

Sousa (2001) afirma que na perspectiva neoliberal, acredita-se que a avaliação, pautada nas características anteriormente citadas, gera competição e, consequentemente, qualidade. O Estado se torna o responsável por fomentar a produção desta qualidade. Desta forma, sob a égide da classificação e da seletividade, políticas educacionais assumem a seleção como inerente aos seus resultados, o que, 


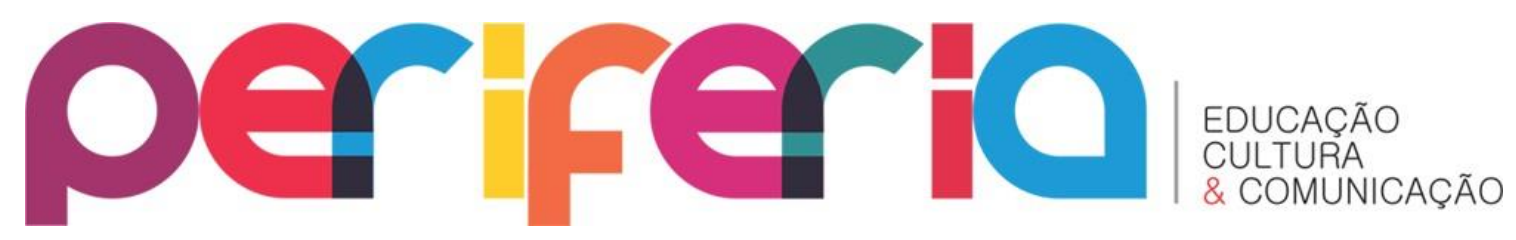

sob meu ponto de vista, é totalmente incompatível com o direito de todos à educação, reduzindo a educação à condição de mercadoria, a partir de uma lógica positivista e mercadológica de ensino.

Pensando ainda na premissa de que a educação é um direito de todos e não é um privilégio para alguns, considero pertinente problematizar a questão da qualidade nesse campo. Para alguns, a mesma está alicerçada em princípios liberais, uma vez que pressupõe a necessidade de selecionar, a partir de princípios meritocráticos, aqueles que deverão continuar seus estudos e ter a possibilidade de galgar os lugares mais privilegiados em nossa sociedade. O que tenho me perguntado, diante de toda esta discussão, é o que pode realmente ser considerada uma educação de qualidade. Qualidade para quem e para o quê? Um sistema altamente excludente, no meu entendimento, não se traduz em qualidade, uma vez que em nome de preparar as crianças para este mundo competitivo, vai deixando muitas crianças à margem, mesmo que de forma velada e disfarçada. Principalmente utilizando o argumento de que todos e todas recebem as mesmas oportunidades escolares, individualizando assim os resultados.

Falando especificamente do cenário público carioca, podemos afirmar que as políticas educacionais implantadas utilizam provas estandardizadas com divulgação de resultados; que a divulgação de rankings de alunos/as e escolas com melhor desempenho acabam se tornando balizadores de um trabalho pedagógico supostamente de qualidade; que a premiação de alunos/as, professores/as e funcionários/as a partir dos resultados obtidos fortalece, cada vez mais, uma política educacional baseada em princípios neoliberais materializados através da meritocracia, competição e seleção. Neste sentido, formulo a seguinte questão: como pensar - e potencializar - uma proposta de escola mais democrática, quando suas diretrizes de avaliação se pautam em princípios como classificação, seleção e competição e desigualdade?

O que precisa ser ressaltado nestas políticas é a centralidade nos aspectos econômicos, deslocando a educação para a esfera do econômico e, 


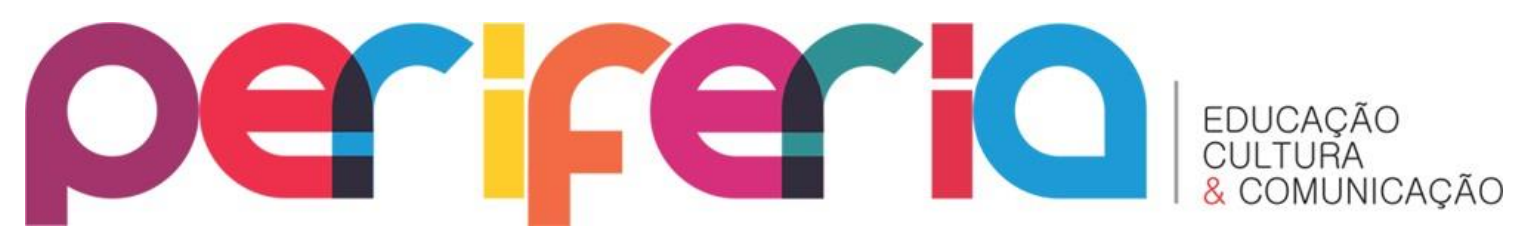

consequentemente, dos modelos gerenciais apregoados pelo mercado. Neste sentido, há uma inversão: o que deveria ser pressuposto de qualidade para a educação pública, garantida e assegurada pelo Estado, passa a ser considerado como deficiência dos usuários. O que deveria ser considerado como direito do cidadão e dever do Estado passa a ser considerado como possibilidade de escolha, a partir do que é considerado como eficiente ou ineficiente dentro deste sistema. Para Harvey (1992), o discurso de um Estado mínimo e descentralizador, embora o mesmo seja o agente das políticas educativas de modo centralizado, serve aos interesses do capital. Ao se isentar da responsabilidade de atender aos direitos básicos dos cidadãos (entre eles a educação), individualiza uma questão que é social, colocando a responsabilidade desta desigualdade nos indivíduos. Ao mesmo tempo em que este Estado se torna mínimo para as políticas sociais e de distribuição de renda, se configura como Estado máximo para os interesses do capital.

Penso que tais avaliações, a partir de uma perspectiva universal de currículo, promovem o silenciamento/ocultamento/invisibilização de outras epistemes. Entendo a complexidade desta discussão, uma vez que qualquer criança tem o direito de ter acesso ao conhecimento escolar. Mas, discordo da necessidade de existirem tais avaliações e da tradução de seus resultados, que são comumente associados a (não) aprendizagem. Penso que a aplicação destas provas não garante a universalização do conhecimento. Servem apenas para acentuar as desigualdades entre crianças e seus processos de aprendizagem, professores e professoras e instituições. Aprender como responder a lógica operatória de uma prova significa que a criança aprendeu a responder corretamente as questões; não necessariamente que ela aprendeu e se apropriou dos conceitos apresentados e pedidos nas provas. Sem contar que elas são um mecanismo de exclusão por excelência, pois aqueles/as que obtém resultados satisfatórios são os/as que conseguem se adequar à sua lógica.

Confesso que este contexto de responsabilização, meritocracia e privatização do ensino me deixa bastante preocupada. A avaliação de desempenho tem direcionado os processos de aprendizagem dos/as meninos/as, em detrimento da 


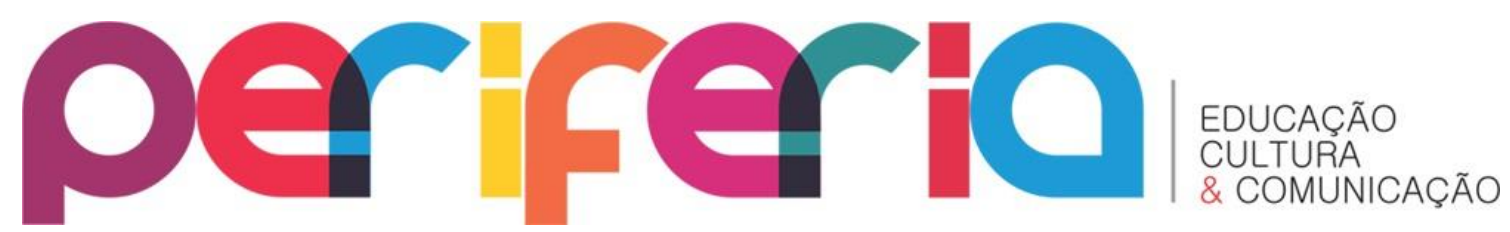

função formativa da avaliação, mais favorável a estes processos. Considero um erro acreditar que índices como o IDEB são a solução para os problemas da educação básica ou para o analfabetismo. Esta "qualidade" está regida pelo viés mercadológico e destitui este termo de seu caráter polissêmico, social, político e histórico. Tais ações, sob meu ponto de vista, contribuem para o empobrecimento da educação e favorecem a lógica da meritocracia e da culpabilização.

Vale também ressaltar que as avaliações em larga escala desconsideram o que acontece cotidianamente nas escolas, assim como suas peculiaridades e necessidades. Elas reduzem o conhecimento a um objeto e à sua dimensão cognitiva, a partir de resultados quantitativos e mensuráveis, que tendem a desvincular estes mesmos conhecimentos das inúmeras relações vivenciadas cotidianamente na escola, entre alunos/as, professores/as e demais atores envolvidos no processo de aprendizagem e de ensino. Defendo que não devem ser utilizadas para criar ranqueamentos, tampouco para justificar a complementação salarial do professor. As avaliações externas e em larga escala dificultam a existência de um processo interno de reflexão das escolas, uma vez que se tornam o parâmetro de qualidade e resumem a participação dos/as professores/as a meros aplicadores das provas (quando não há aplicadores externos, como em alguns casos).

\section{REFERÊNCIAS}

AFONSO, A. J. Avaliação educacional: regulação e emancipação: para uma sociologia das políticas avaliativas contemporâneas. São Paulo: Cortez, 2000.

Um olhar sociológico em torno da accountability em educação. In: ESTEBAN, M. T.; AFONSO, A. J. (Orgs.). Olhares e interfaces: reflexões críticas sobre a avaliação. São Paulo: Cortez, 2010.

. Para uma conceitualização de alternativa de accountability em educação.

Educ. Soc., Campinas, v. 33, n. 119, p. 471-484, abr./jun. 2012. Disponível em: <http://www.redalyc.org/articulo.oa?id=87323122007>. Acesso em: 27 fev. 2015.

BRASIL. Plano Nacional de Educação 2011-2020. Projeto de Lei n. 8035, 2010. Brasília, DF: Senado Federal, 2010a.

BRASIL. Ministério da Educação. Secretaria de Educação Fundamental. Referencial Curricular Nacional para a Educação Infantil. Brasília, DF, 1998. v. 2. 


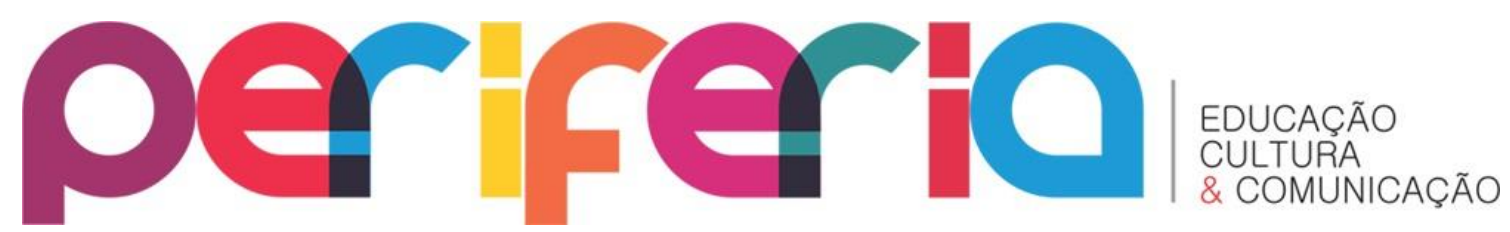

BRASIL. Ministério da Educação. Secretaria de Educação Básica. Diretrizes Curriculares Nacionais para a Educação Infantil. Brasília, DF, 2009.

CARVALHO, G. F. da S.; MACEDO, M. do S. A.N. Avaliação oficial: o que dizem os mediadores da política pública sobre o impacto na prática docente. Revista Estudos em Avaliação Educacional, São Paulo, v. 21, n. 46, p. 253-270, maio/ago. 2010. Disponível em: <http://www.fcc.org.br/institucional/2011/01/17/1659/>. Acesso em: $27 \mathrm{fev}$. 2015.

CONSELHO NACIONAL DE EDUCAÇÃO (Brasil). Notas Técnicas PNE 2011-2020. Brasília, DF, 2010.

FELICIO, F.; VASCONCELLOS, L. O efeito da educação infantil sobre o desempenho escolar medido em exames padronizados. In: ENCONTRO NACIONAL DE ECONOMIA, 35., 2007, Recife. Anais eletrônicos... Disponível em: <http://www.anpec.org.br/encontro2007/artigos/A07A093.pdf>. Acesso em: $27 \mathrm{fev}$. 2015.

FREITAS, L. C. Eliminação adiada: o ocaso das classes populares no interior da escola e a ocultação da (má) qualidade do ensino. Educ. Soc., Campinas, v. 28, n. 100, p. 965987, out. 2007.

FREITAS, L. C. et.al. Avaliação educacional: caminhando pela contramão. 4. ed. Petrópolis: Vozes, 2012.

HARVEY, D. Condição pós-moderna. São Paulo: Loyola, 1992.

HYPOLITO, Á. M. Políticas curriculares, estado e regulação. Educ. Soc., Campinas, v. 31, n. 113, p. 1337-1354, out.-dez.2010.

NEVES, V. F. A. Avaliação na educação infantil: algumas reflexões. In: REUNIÃO ANUAL DA ASSOCIAÇÃO NACIONAL DE PÓS-GRADUAÇÃO E PESQUISA EM EDUCAÇÃO, 35., 2012, Porto de Galinhas. Anais eletrônicos... Disponível em: <http://35reuniao.anped.org.br/images/stories/trabalhos/GT07\%20Trabalhos/GT071452_int.pdf>. Acesso em: 27 fev. 2015.

SOUSA, S. M. Z. L. Avaliação e políticas educacionais: iniciativas em curso no Brasil. In: HIDALGO, A. M.; SILVA, I. L. F. Educação e Estado: as mudanças nos sistemas de ensino do Brasil e Paraná na década de 90. Londrina: Ed. UEL, 2001. 